\title{
Explanation of Normative Declines in Parents' Knowledge about their Adolescent Children
}

\author{
J. Gowert Masche \\ Kristianstad University \\ Paper presented at the 20th Biennial ISSBD Meeting, \\ Würzburg, Germany, July 13-17, 2008
}




\section{Background}

- Parental knowledge: "Do your parents know about what you do in your spare time?" Knowledge about child's whereabouts, school, and spending allowances

- In the past, parental knowledge used as measure for "monitoring": Correlations with low levels of problem behavior seen as result of parenting style

- But knowledge stems to the largest part from adolescent disclosure and not from parental control (Stattin \& Kerr, 2000)

- This literature misses the developmental aspect: Parental knowledge declines as a norm (Masche, 1998, 2006)

- Why declines knowledge on average, although high levels of knowledge are related to positive development? 


\section{Parental knowledge might decline because...}

- Adolescents try to become autonomous

- Own territories (Youniss \& Smollar, 1985): areas that parents do not any longer know about

- Own decisions

- Parents might adapt to adolescents' autonomy needs (Hofer, 2003)

- Reduced control

- Adolescents establish new relations outside the family, which might detract them from close family relations 


\section{Logic of analyses}

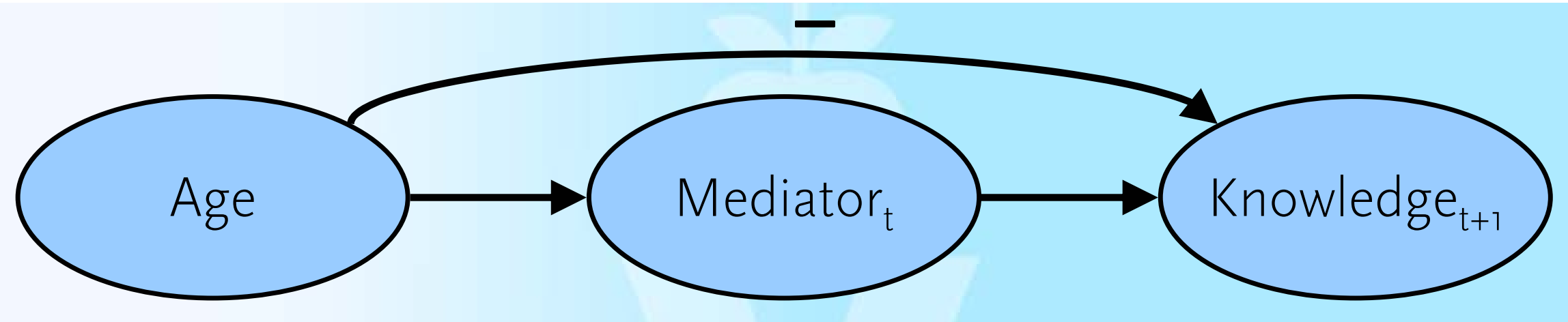




\section{Logic of analyses}

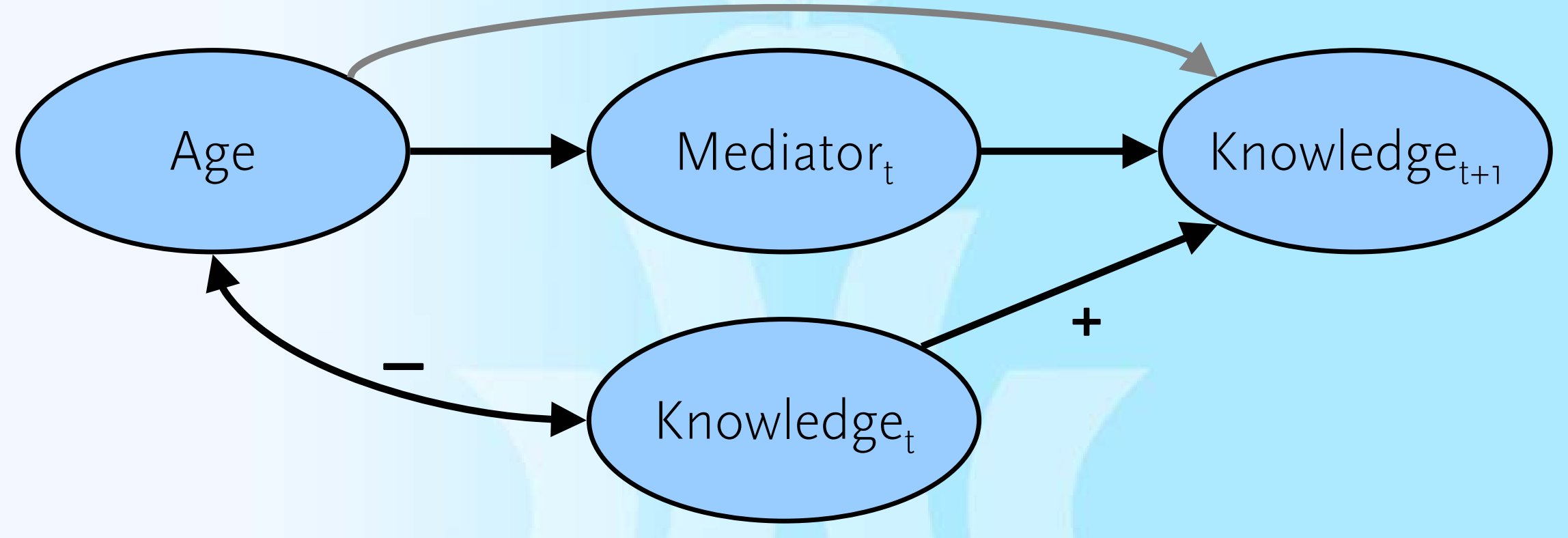




\section{Sample}

\begin{tabular}{|c|c|c|c|c|c|c|}
\hline 1991 & & & Age & 13 & 14 & \multirow{9}{*}{$\begin{array}{l}N=2,415 \\
1,222 \text { boys, } 1,193 \text { girls } \\
4,875 \text { questionnaires, } \\
\text { with further questionnaire } \\
\text { even at } t+1\end{array}$} \\
\hline 1990 & & & 13 & 14 & 15 & \\
\hline 1989 & & 13 & 14 & 15 & 16 & \\
\hline 1988 & 13 & 14 & 15 & 16 & 17 & \\
\hline 1987 & 14 & 15 & 16 & 17 & 18 & \\
\hline 1986 & 15 & 16 & 17 & 18 & & \\
\hline 1985 & 16 & 17 & 18 & & & \\
\hline \multirow[t]{3}{*}{1984} & 17 & 18 & & & & \\
\hline & 2001 & 2002 & 2003 & 2004 & 2005 & \\
\hline & & & r of su & & & \\
\hline
\end{tabular}




\section{Sample}

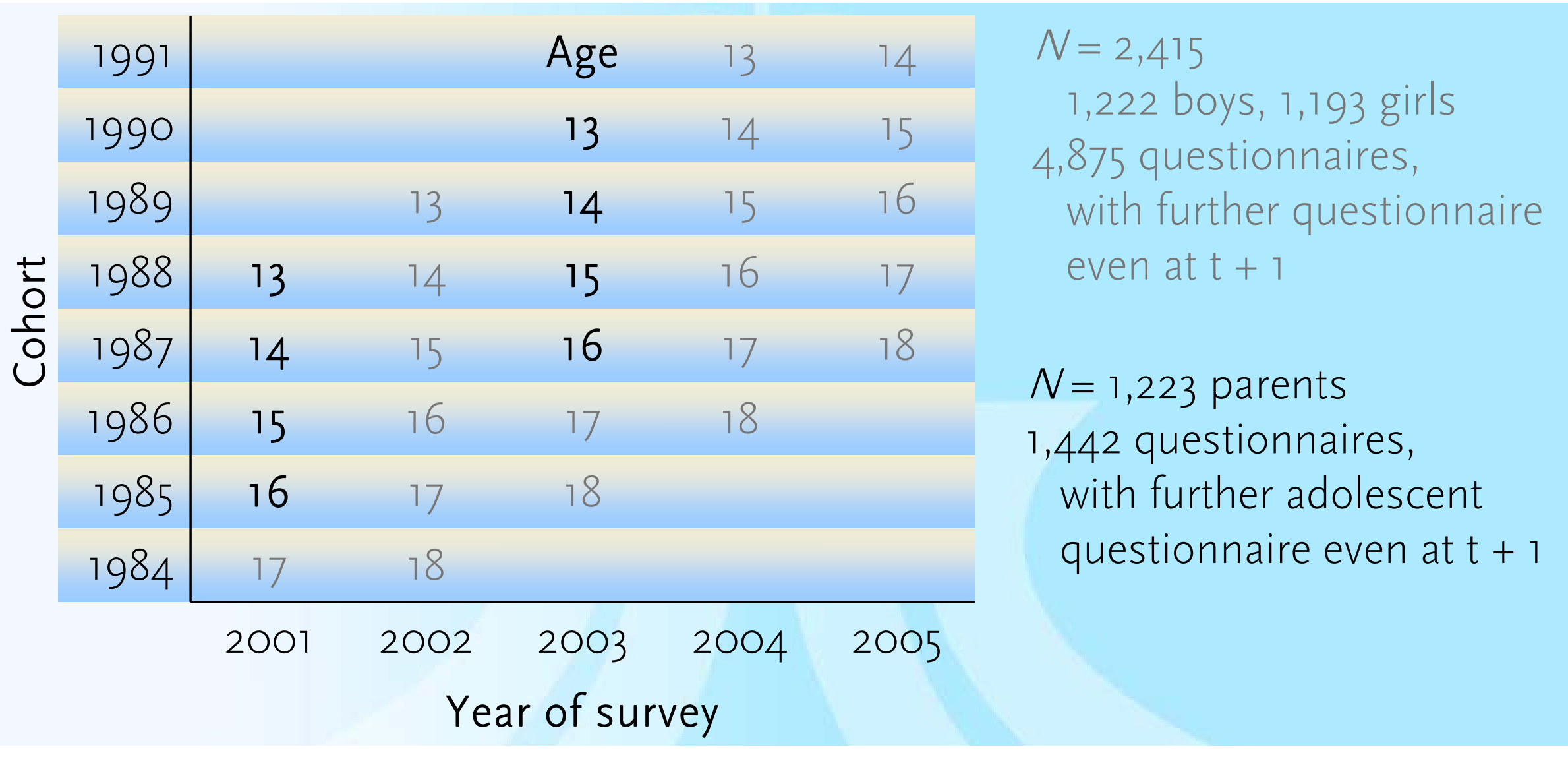




\section{Multi-level analyses}

- Level 1: within individual Mediation analysis as shown before

- Level 2: between individuals

Effects of cohort and gender on intercepts and regression weights

- This implies...

- Main effects of cohort and gender are controlled

- Interactions of cohort and gender with study variables are tested

- Test of mediation effects at varying numbers of occasions per individual 


\section{Age decline of parental knowledge}

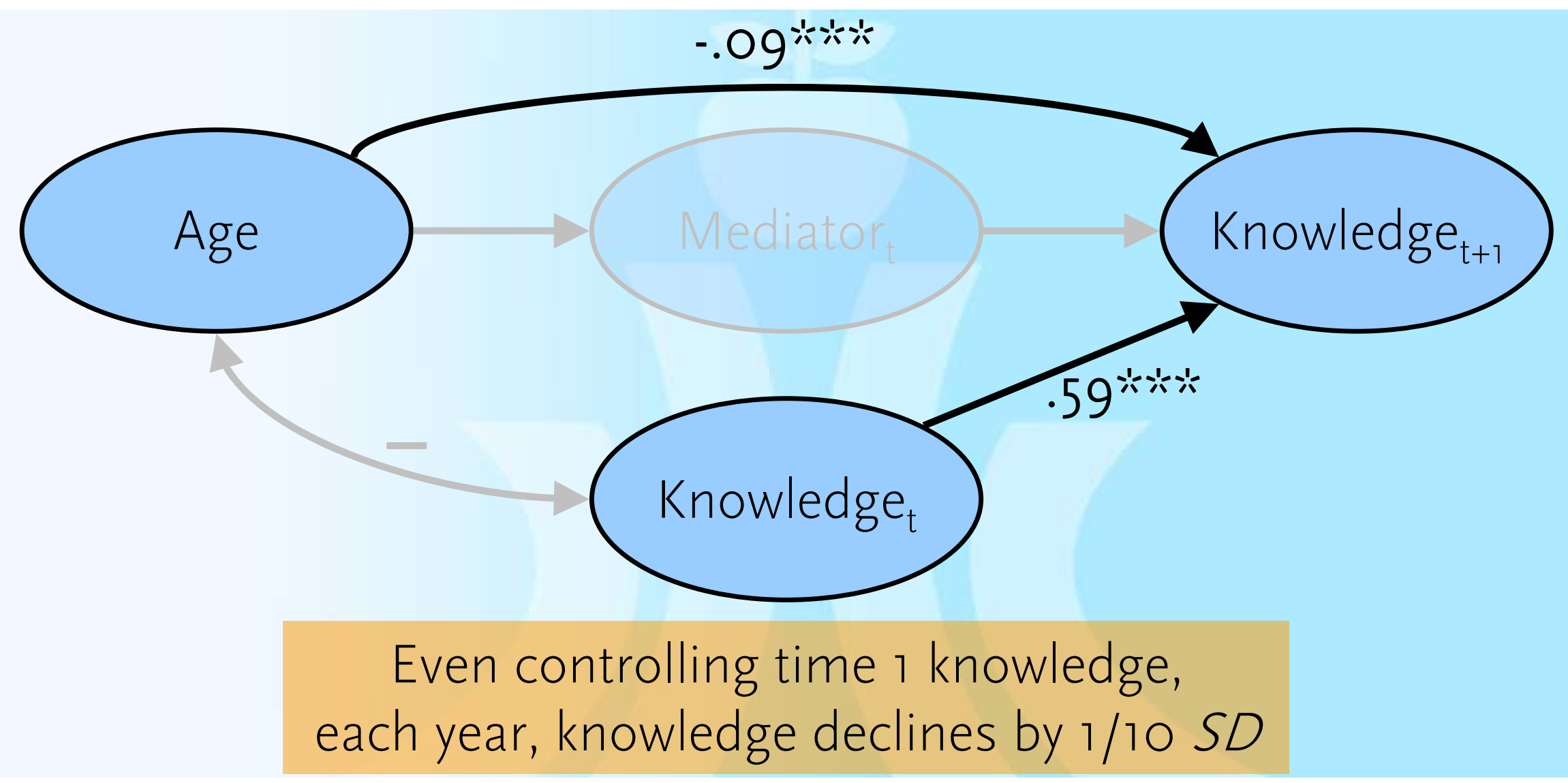

www.hkr.se 


\section{Test of mediation: I. Private territories}

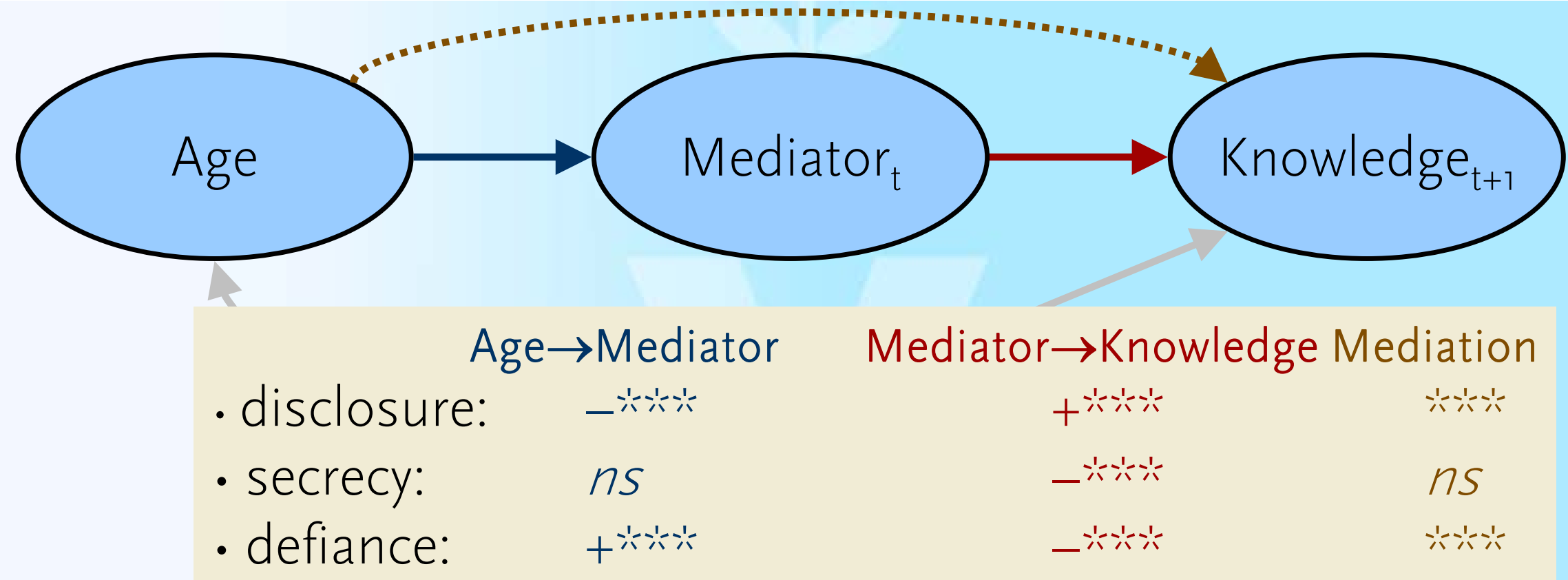

Adolescents' information management and claims of increased autonomy, but not secrecy, explain normative decline of parental knowledge. 


\section{Test of mediation: II. Parental monitoring, etc.}

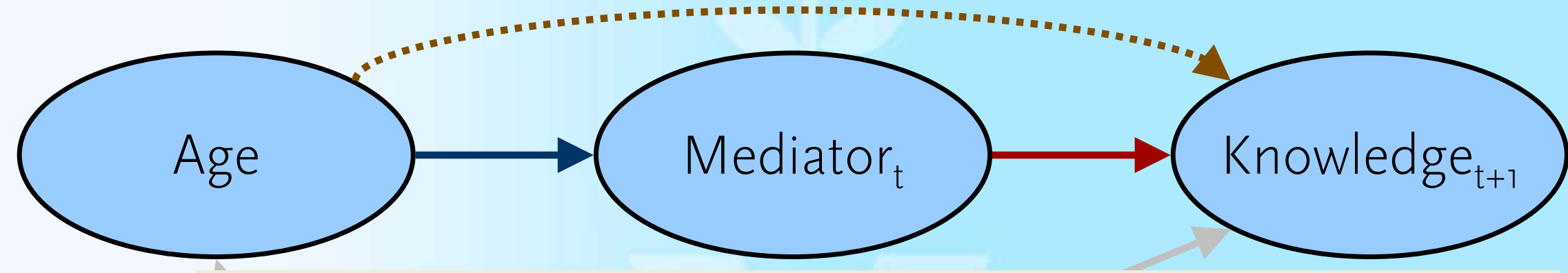

Age $\rightarrow$ Mediator Mediator $\rightarrow$ Knowledge Mediation

- control: 一次次次

$+2 \cdot x$

次次

- overcontrol: _共站

一汒次

决次

- solicitation: +次次

+ 头

$\dot{x}$

- democracy:

nS

十穴穴次

$n S$

Ambiguous effect: Decreasing control reduces knowledge, but bothering adolescents less with overcontrol and asking them more slows down the decline in knowledge. 


\section{Test of mediation: III. Relations outside family}

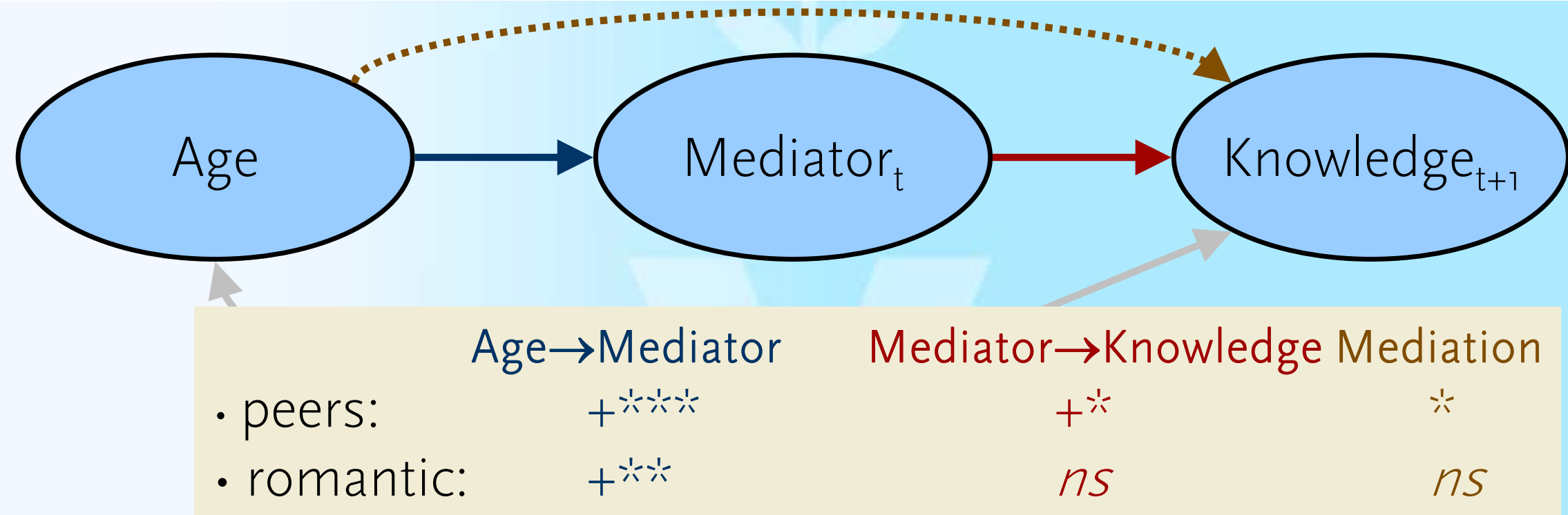

Although adolescents enhance their relations outside the family, this rather contributes to parental knowledge, thus, slows down the age-decline. 


\section{Test of mediation: IV. Parent-reported mediators}

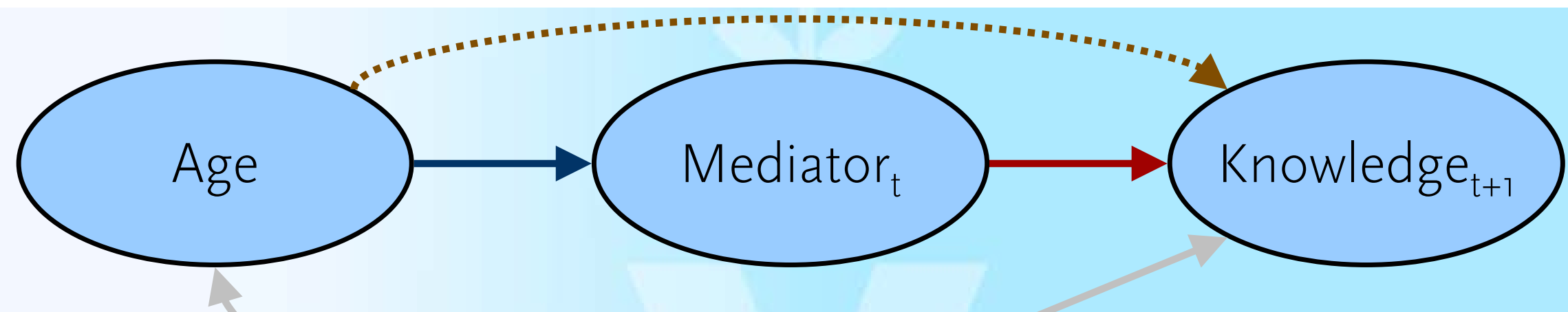

Age $\rightarrow$ Mediator Mediator $\rightarrow$ Knowledge Mediation

- disclosure: ns

十穴穴

nS

- trust:

ns

ns

ns

- worries:

ns

ns

ns

- avoidance of confrontation: ns

- giving up:

ns

ns

ns 


\section{Why do parent-reports not explain knowledge decline?}

- In subsample with parent data, no significant age decline in knowledge (-.02 ns)

- restricted sub-group

- restricted age-range

- Parents do not perceive changed relationship

- same reasons as above

- smaller sample-size, most parents assessed only once

- largely "pathologic" scales 


\section{Unique and combined mediation effects}

- Three mediators explained age decline of parental knowledge: Adolescent disclosure \& defiance, parent control

- But they might overlap and might actually not be independent.

- When entering all of them in the regression equation, do they still predict parental knowledge?

- Disclosure: .17****

- Defiance: -.04*

- Control: .06 ns

- Combined, these variables explain $38.7 \%$ of age decline in parental knowledge. 


\section{Gender}

- Somewhat mixed gender main effects and age-by-gender interactions

- For 2 out of 14 potential mediator variables, differential effects at $p<.05$ : Effects of disclosure and low secrecy on parental knowledge somewhat weaker in girls

- Still, all mediation effects which are significant in general, are so for each gender 


\section{Cohort}

- Nothing that would affect the mediation analyses

- Some main effects, independent of age:

- parents know less about later-born youth

- more control \& solicitation with later-born youth, less avoidance of confrontation (parent-report), better friendships

- cohort main effects and cohort-by-age interactions which actually reflect curvilinear age trends (see next slide) 


\section{Cohort}

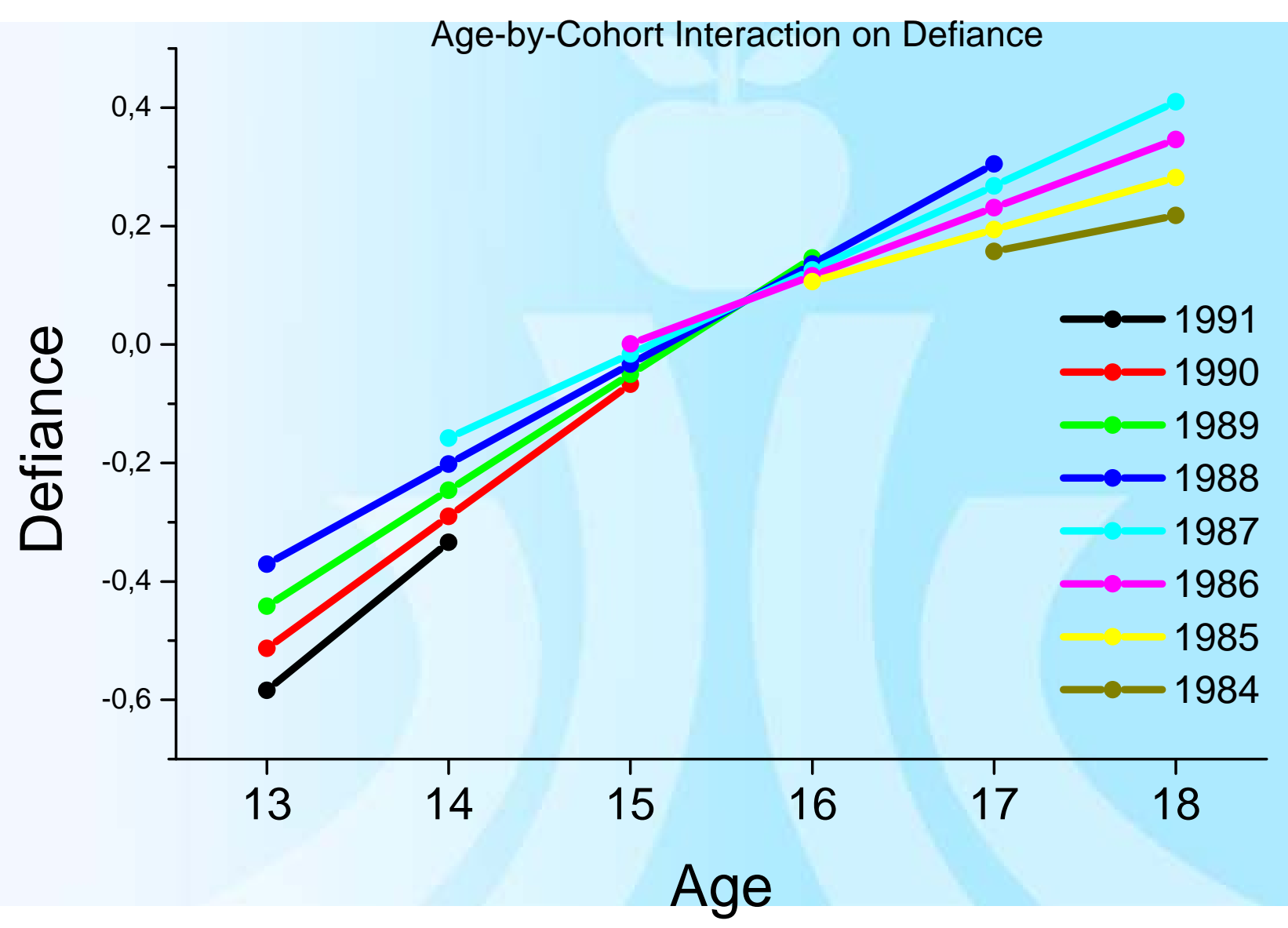




\section{Discussion}

- Longitudinal multi-level analysis of mechanisms that lead to decreased knowledge

- Adolescents' establishment of private territories leads to reduced parental knowledge: less disclosure of information, more defiance

- Also reduced parental control explains less knowledge, but is spurious if controlling disclosure and defiance

- Families also slow down loss of parental knowledge:

- Parents reduce overcontrol and increase solicitation: adaptation towards more lenient ways of control (Hofer, 2003)

- More satisfied peer relations: Transferring peer experiences to parent relationships (Youniss \& Smollar, 1985)?

- Core results largely gender and cohort independent 


\section{Take-home message \& outlook}

- Parental knowledge mirror of parent-adolescent relationships

- Adolescents drive their development towards autonomy

- Both generations also slow down this development: driving and delaying processes are balanced and maybe coordinated

- Precociously low levels of parental knowledge might indicate lack of balance \& coordination and need to be distinguished from the normative development towards autonomy 